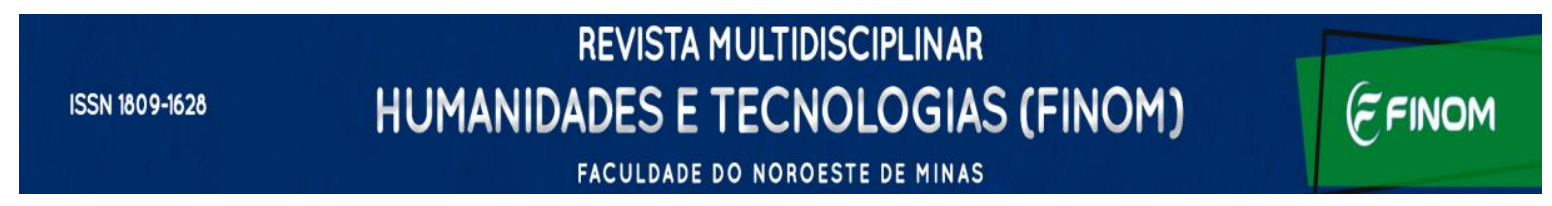

\title{
Desafios e utopias nas escolas públicas paulistas: um (re)olhar sobre o descritor "desigualdade socioeconômica"1
}

\author{
Challenges and utopias in the paulista's public schools: \\ a (another) look at descriptor "socioeconomic inequality"
}

\author{
Luciane Helena Mendes de Miranda ${ }^{2}$ \\ Vera Maria Nigro de Souza Placco ${ }^{3}$ \\ Patrick Vieira Ferreira ${ }^{4}$ \\ Dilma Antunes Silva ${ }^{5}$
}

\begin{abstract}
Resumo: Este trabalho apresenta um recorte da pesquisa "Qual a escola para o século XXI?", desenvolvida pelo Grupo de Pesquisa CEPId, da PUC-SP. A temática das desigualdades socioeconômicas evidenciada nas escolas públicas, é tomada como questão norteadora, neste texto, a fim de analisar se e quais desafios são colocados às escolas da atualidade. Os dados foram produzidos através de um survey, com participação de 5005 profissionais da educação atuantes no âmbito da Secretaria Estadual de Educação de São Paulo (Seduc-SP). Os resultados apontam para um conjunto de fatores desafiantes vivenciados tanto pelos profissionais como pelos estudantes, os quais têm se acentuado ainda mais devido ao contexto da pandemia de Covid-19.
\end{abstract}

\footnotetext{
${ }^{1}$ Para fins desta pesquisa, consideramos como "descritor" um conjunto de expressões que identificam situações relacionadas às formas de desigualdade presentes na sociedade, com impactos também na escola. Compreendemos a desigualdade socioeconômica como uma das matizes da estrutura social desigual, injusta e excludente historicamente arraigada nos territórios onde a pesquisa se realiza, afetando direta e indiretamente um grande número de indivíduos e coletividades.

2 Doutora em Educação: Psicologia da Educação pela Pontifícia Universidade Católica de São Paulo. Psicóloga escolar. Pesquisadora do Grupo de Pesquisa Contexto Escolar, Processos Identitários da Formação de Professores e Alunos da Educação Básica - CEPId, da PUC-SP. E-mail: lucianemmiranda @ gmail.com

${ }^{3}$ Professora no Programa de Pós-Graduação em Educação: Psicologia da Educação, PUC-SP. Coordenadora do Grupo de Pesquisa Contexto Escolar, Processos Identitários da Formação de Professores e Alunos da Educação Básica (CEPId). E-mail: veraplacco@ @ucsp.br

${ }^{4}$ Doutor em Educação: Psicologia da Educação pela Pontifícia Universidade Católica de São Paulo. Pesquisador do Grupo de Pesquisa Contexto Escolar, Processos Identitários da Formação de Professores e Alunos da Educação Básica - CEPId, da PUC-SP. E-mail: prpatrickvf@gmail.com

${ }^{5}$ Doutora em Educação: Psicologia da Educação pela Pontifícia Universidade Católica de São Paulo. Docente EBTT na Universidade Federal de São Paulo (Unifesp), Pesquisadora do Grupo de Pesquisa Contexto Escolar, Processos Identitários da Formação de Professores e Alunos da Educação Básica - CEPId, da PUC-SP. E-mail: dilmasilva7@hotmail.com
}

Recebido em 23/01/2022

Aprovado em 10/02/2022

Sistema de Avaliação: Double Blind Review

OPEN ACCESS 


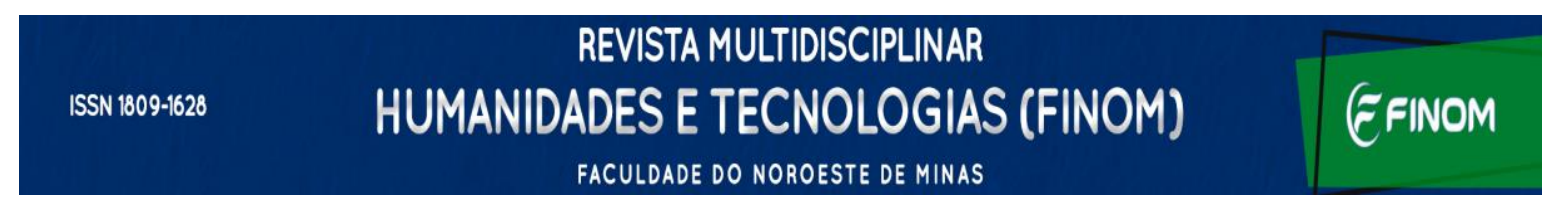

Palavras-chave: Profissionais da educação. Escola pública paulista. Desigualdades socioeconômicas. Desafios. Políticas educacionais.

\begin{abstract}
This work presents an excerpt from the research "Which is the school for the 21st century?", developed by CEPId Research Group, at PUC-SP. The theme of socioeconomic inequalities evidenced in public schools is taken as a guiding question, in this text, in order to analyze if and what challenges are for schools today. The data were found through a survey, with the participation of 5005 education professionals working in the scope of the Education Department of São Paulo State (SEDUC-SP). The results point to a set of challenging factors experienced by both professionals and students, which have become even more accentuated due to the context of the Covid-19 pandemic.
\end{abstract}

Keywords: Education professionals. São Paulo public school. Socioeconomic inequalities. Challenges. Educational policies

\title{
Introdução
}

Os contextos de vulnerabilidades estão relacionados às situações que um sujeito ou grupo vivencia na escola, sua relação e dificuldades encontradas pelos profissionais da educação, conceito este que é basilar nesta pesquisa, sendo assim, temos como problema norteador desta investigação: Como o tema desigualdades socioeconômicas é evidenciado nas escolas públicas paulistas da atualidade? Como objetivo geral, buscamos identificar e compreender esse tema e suas faces no cotidiano das escolas paulistas. Para tanto, realizamos uma pesquisa qualitativa envolvendo diferentes profissionais da educação (docentes, gestores e técnicos) ligados à Secretaria Estadual de Educação de São Paulo (Seduc-SP), que teve como método a aplicação de um questionário virtual do tipo survey e, em complementaridade realizou-se um levantamento de pesquisas correlacionadas e a análise das publicações oficiais da Seduc-SP.

Vale destacar que este texto resulta de um recorte da pesquisa ${ }^{6}$ que vem sendo desenvolvida no âmbito do Grupo de Pesquisa Contexto Escolar, Processos Identitários da Formação de Professores e Alunos da Educação Básica (CEPId), da PUC-SP, cujo objetivo é o de investigar as concepções de escola para o século XXI, suas finalidades educativas, objetivos e atributos trazidos por professores, gestores e outros atores que dialogam com esta

\footnotetext{
${ }^{6}$ A pesquisa "Desafios da escola na atualidade: Qual a escola para o século XXI? Uma pesquisa com diversos atores, no estado de São Paulo”, desenvolvida no período de 2015 a 2021, estrutura em cinco eixos, a saber: 1) Condições de Trabalho Docente; 2) Finalidades Educativas Escolares; 3) Formação Inicial e Continuada de Professores; 4) Tecnologia e 5) Vulnerabilidades.
} 


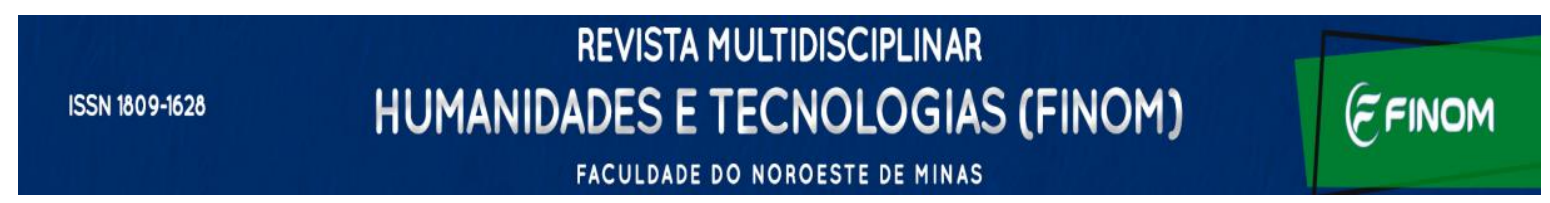

instituição, a fim de identificar e analisar mecanismos de superação dos desafios da escola, como possibilidades de encaminhamento às questões levantadas.

\section{Metodologia}

Segundo Tim May (2004), as surveys são um dos métodos mais utilizados nas pesquisas sociais e caracterizam-se pela produção de dados de um número grande ou muito grande de pessoas, podendo ser locais e ou de larga escala. Para fins deste estudo, o públicoalvo da survey foram professores dos anos finais do Ensino Fundamental, coordenadores, diretores e vice-diretores, supervisores de ensino e dirigentes de Diretorias de Ensino (DE) e outros profissionais da rede estadual de ensino de São Paulo.

O instrumento para coleta das informações de interesse da investigação continha 45 questões, sendo 25 de caracterização dos sujeitos e as demais, relacionadas com os eixos estruturantes da pesquisa, e foi encaminhado por e-mail a esses profissionais, via Escola de Formação e Aperfeiçoamento dos Profissionais da Educação (Efape), no período de agosto de 2018 a abril de 2019, com o alcance de 5005 respondentes, vinculados a 91 Diretorias de Ensino (DE), da capital, Grande São Paulo, interior e litoral.

Os dados foram analisados estatisticamente com uso do software SPSS (Statistical Package for the Social Sciences), possibilitando uma análise crítica através da produção de tabelas e gráficos.

Caracterização dos sujeitos

Os sujeitos participantes desta pesquisa, como citado anteriormente, são professores dos anos finais do Ensino Fundamental, coordenadores, diretores e vice-diretores, supervisores de ensino e dirigentes de DE e outros profissionais da rede estadual de ensino de São Paulo, foi necessária também a orientação para que os sujeitos, caso trabalhassem em mais de uma escola, escolhessem apenas uma para responder ao questionário.

Os respondentes são em sua maioria, do gênero feminino (72\%), masculino (27\%) e 0,9\% não declarados, sendo a opção "outros" assinada por $0,1 \%$. Possuem idade média entre 45 a 49 anos e tempo de atuação na rede de ensino de entre 11 a 21 anos. Quanto à raça/etnia, $77,2 \%$ se autodeclararam brancos, $14,9 \%$ pardos, 5,4\% pretos, 0,9\% amarelos; 0,3\% indígenas. Preferiram não declarar pertencimento racial/étnico $1,4 \%$.

Do universo participante - 5005 profissionais da Seduc-SP-, 64,9\% são professores, 


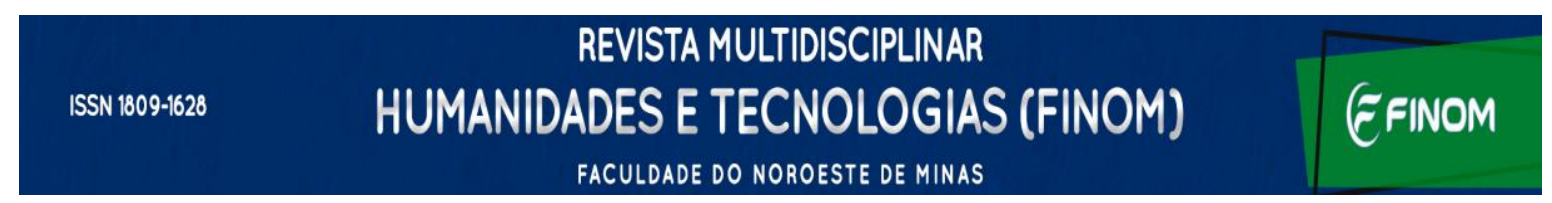

13,3\% coordenadores; $11 \%$ diretores escolares; $5,2 \%$ vice-diretores; $2,1 \%$ dirigentes de ensino; $1,7 \%$ supervisores; $1 \%$ professores mediadores. O percentual de profissionais que responderam "Não se aplica" quanto a função desempenhada no âmbito desta rede de ensino, perfaz $1,1 \%$.

Os respondentes, em sua maioria, são residentes e atuam na região urbana (96\%). Quanto a sua categoria funcional, $77,60 \%$ são efetivos na rede estadual de ensino, os profissionais contratados e eventuais somam $10,77 \%$; $11,63 \%$ responderam "não se aplica". Referente ao regime de trabalho evidencia-se maior adesão pelo tempo parcial, isto é, jornada de trabalho de até 20 horas $(76,1 \%)$. Já as jornadas em tempo integral (40 horas) são cumpridas por 16,6\% dos respondentes e, 7,2\% fazem parte do Regime de Dedicação Plena e Integral - PEI (40 horas em período integral).

O questionário também contemplou questões referentes ao acesso a bens e serviços sociais e culturais pelos participantes. A tabela a seguir mostra quais serviços e ou bens públicos estão mais acessíveis a um número maior de respondentes.

Tabela 1- Serviços disponíveis nas regiões onde os respondentes atuam

\begin{tabular}{|l|r|r|}
\hline \multicolumn{3}{|c|}{ Serviços disponíveis } \\
\hline & Freq. & \% \\
\hline Luz & 4761 & 95,1 \\
\hline Coleta de lixo & 4745 & 94,8 \\
\hline Água/esgoto & 4678 & 93,5 \\
\hline Transporte & 4379 & 87,5 \\
\hline Posto de saúde & 4339 & 86,7 \\
\hline Farmácia & 4301 & 85,9 \\
\hline Creche/Educação Infantil & 4232 & 84,6 \\
\hline Agência de correios & 3359 & 67,1 \\
\hline Espaço Públicos & 3138 & 62,7 \\
\hline Agência bancária & 3121 & 62,4 \\
\hline Segurança & 2716 & 54,3 \\
\hline Hospital & 2472 & 49,4 \\
\hline Nenhum & 55 & 1,1 \\
\hline \multicolumn{2}{|r|}{ Fonte: CEPId, PUC-SP (2019). } \\
\hline
\end{tabular}

Após essa breve caracterização, apresentaremos de forma sucinta o conjunto de descritores gerados a partir das análises dos dados. 


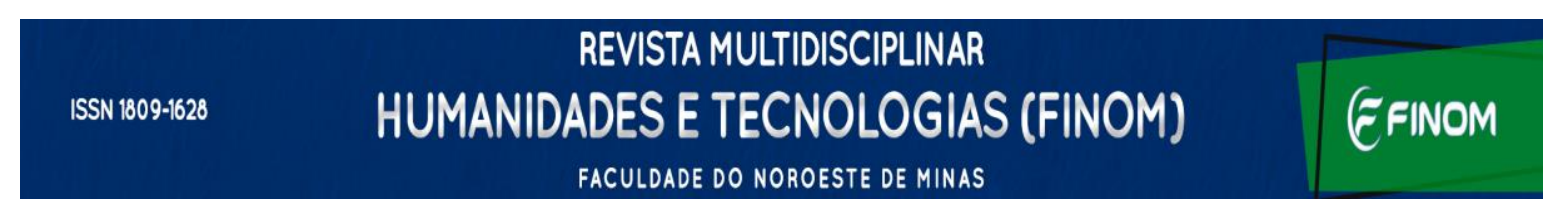

Descritores de análise

Os principais descritores de vulnerabilidade, obtidos na pesquisa, originam-se de uma questão que buscou identificar quais são os principais temas, relacionados à vulnerabilidade, que permeiam o cotidiano desses escolares. Em síntese, são 16 os descritores apontados pelos sujeitos: 1. aborto; 2. agressão física entre colegas; 3. automutilação; 4. depressão; 5. desigualdades socioeconômicas; 6. dificuldade de aprendizagem; 7. drogas; 8. família; 9. gênero; 10. pessoas com deficiência; 11. questões emocionais; 12. redes sociais; 13. relações étnico-raciais; 14. sexualidade; 15. suicídio e, 16. violência. A fim de garantir a padronização das respostas (MAY, 2004) referentes à questão do eixo Vulnerabilidades, a survey foi planejada de modo que os sujeitos respondessem: (1) quais temas eram considerados importantes para serem abordados nas escolas; (2) quais deles já eram abordados na escola; (3) quais temas são desafiantes e precisam de intervenção nas escolas e; (4) nenhuma das anteriores (NDA), caso sua resposta não tivesse sido contemplada pelas opções anteriores. As respostas foram convertidas em gráficos para facilitar a compreensão e visualização dos dados, bem como, possibilitar diferentes combinações e análises. Neste texto, a análise compreenderá o descritor 5- desigualdades socioeconômicas, relacionando-o com as concepções dos sujeitos respondentes quanto à função da escola pública na atualidade.

\section{Fundamentação teórica}

Para compreender claramente a escola da atualidade é preciso investigar as vulnerabilidades dos sujeitos e seus grupos pertencentes a esta instituição e as realidades e contextos expostos evidenciando a pluralidade social existente nela.

O conceito de vulnerabilidade vem sendo amplamente utilizado em estudos de diferentes áreas, entre elas a Psicologia e a Educação, assumindo diversas significações (SCOTT et al., 2018). No atual contexto pandêmico, passou a ser um termo recorrente nos discursos políticos, jornalísticos/midiáticos, acadêmico, científico etc., em geral, acompanhado da constatação de sua ampliação e de seus efeitos negativos sobre populações e grupos minorizados historicamente, como nos lembra Santos (2020). Apesar disso, ele não é novo. Luciane

O termo introduzido, inicialmente, na área jurídica internacional, difundiu-se no 


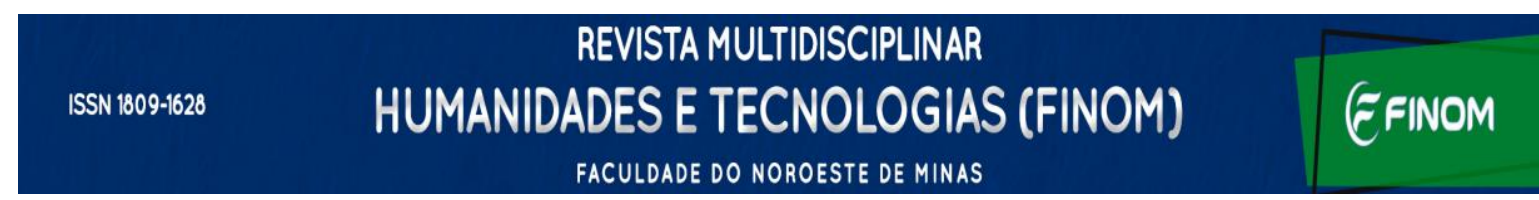

campo da saúde pública, na década de 1980, como resposta à epidemia do Vírus da Imunodeficiência Humana (HIV)/Síndrome da Imunodeficiência Adquirida (Aids/Sida), referindo-se à pessoas ou grupos que apresentavam uma gama maior de fatores associados à patogenia do vírus (SCOTT et al., 2018).

O conceito de vulnerabilidade também foi, por longo período, associado a indicadores de pobreza. Entretanto, segundo Adorno (2001) e Carmo e Guizardi (2018), é possível compreendê-lo, para além dessa dimensão, sem, no entanto, desconsiderar que estão atrelados. A vulnerabilidade denota multideterminação e atenta-se para um conjunto de fatores que permeiam e caracterizam as condições de vida das populações e grupos que se encontram em situação de suscetibilidade em decorrência da desigualdade e injustiça social. Scott et al. (2018, p. 602) corrobora essa ideia, ao afirmar que esse conceito dirige-se "para os diferentes contextos sociais como determinantes de variadas suscetibilidades."

Nessa direção, Adorno (2001), apresenta a ideia de "rede de oportunidades disponíveis" frente às reais possibilidades de acesso por parte da população, a bens e serviços públicos, que constituem direitos de cidadania. Nas palavras do autor:

O termo vulnerabilidade carrega em si a ideia de procurar compreender
primeiramente todo um conjunto de elementos que caracterizam as condições de
vida e as possibilidades de uma pessoa ou de um grupo - a rede de serviços
disponíveis, como escolas e unidades de saúde, os programas de cultura, lazer e de
formação profissional, ou seja, as ações do Estado que promovem justiça e cidadania
entre eles - e avaliar em que medida essas pessoas têm acesso a tudo isso. Ele
representa, portanto, não apenas uma nova forma de expressar um velho problema,
mas principalmente uma busca para acabar com velhos preconceitos e permitir a
construção de uma nova mentalidade, uma nova maneira de perceber e tratar os
grupos sociais e avaliar suas condições de vida, de proteção social e de segurança. É
uma busca por mudança no modo de encarar as populaçôes-alvo dos programas
sociais (ADORNO, 2001, p.12).

Adorno (2001) nos ajuda a compreender que, embora seja este um termo amplamente adotado no contexto das políticas públicas de saúde e assistência social, e mais recentemente incorporado às políticas educacionais, é preciso considerar seus impactos diretos nos processos de ensino-aprendizagem, uma vez que seu uso nos permite ampliar o olhar acerca dos "múltiplos fatores que fragilizam os sujeitos no exercício de sua cidadania" (CARMO; GUIZARDI, 2018, p.1), sendo a educação, seus atores e seus processos, importantes dimensões a serem consideradas.

A Constituição Federal de 1988 (CF/1988), em seu artigo 3º, estabelece os objetivos fundamentais que buscam evidenciar os princípios da cidadania e da dignidade da pessoa, presentes no ordenamento jurídico brasileiro e que também fundamentam as políticas 


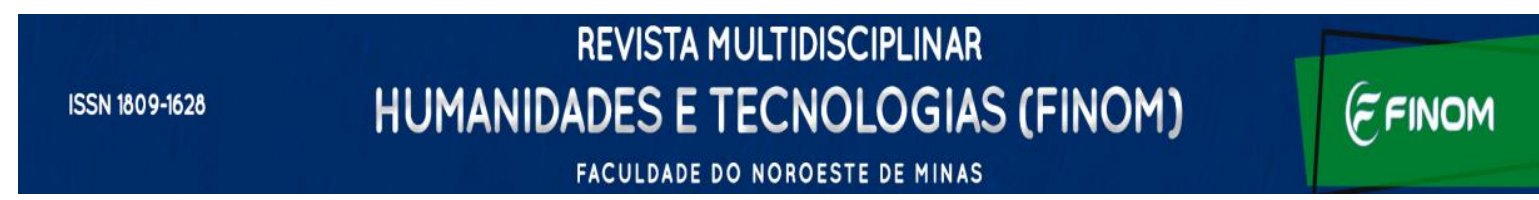

educacionais e propostas pedagógicas das instituições escolares. Desses objetivos destacamos o terceiro, que versa sobre a erradicação da pobreza e da marginalização e visa reduzir as desigualdades sociais e regionais, isto nos remete ao fundamento da igualdade, um dos pilares estruturantes de nossa sociedade.

Ao abordamos o conceito de vulnerabilidades, consideramos a contribuição de Mann,Tarantola e Netter (1992) que consideram de grande relevância a compreensão deste conceito e de suas implicações na vida daqueles (as) que são considerados "fragilizados ou suscetíveis" social, jurídica ou politicamente, na promoção, proteção e/ou garantia dos seus direitos fundamentais. Ampliando esta definição, Carmo e Guizardi (2018, p.7), apontam que "o conceito de vulnerabilidade é adjetivado pelo termo social, que indica a evolução do entendimento acerca das privações e desigualdades ocasionadas pela pobreza. Nessa direção, Monteiro (2001, p.31) argumenta:

O tema da vulnerabilidade social [...] caracteriza-se por um complexo campo conceitual, constituído por diferentes concepções e dimensões que podem voltar-se para o enfoque econômico, ambiental, de saúde, de direitos, entre tantos outros. Ainda que essa temática venha sendo trabalhada ao longo de anos, cabe salientar que ela consiste em um conceito em construção, tendo em vista sua magnitude e complexidade.

Destarte, Abramovay (2002) compreende a vulnerabilidade social como um conceito amplo e multidimensional, que engloba questões relacionadas ao acesso a serviços e direitos básicos de cidadania, como condições habitacionais, sanitárias, educacionais, de trabalho, de participação e acesso à informação e oportunidades oferecidas amplamente àqueles que possuem essas condições, também na perspectiva da ausência de proteção e auxílio do Estado com determinado grupo populacional quanto a políticas públicas voltadas à universalização dos direitos e acessos.

Por fim, Raoport e Da Silva (2013), nos apresentam algumas características da vulnerabilidade social: subnutrição, alteração no desenvolvimento psicomotor, ferimentos por falta de supervisão, déficit de concentração, culpa, danos no desenvolvimento da personalidade, quadros psicopatológicos, depressão, agressividade, suicídio, medo, abuso físico e ou sexual entre outros. Salientamos que muitas dessas características foram identificadas pelos sujeitos da pesquisa como fatores desafiantes à escola e à prática docente.

Sabemos que a definição de marcos conceituais para o tema da vulnerabilidade social é necessária, e como explicam Monteiro (2001) e Carmo e Guizardi (2018), esta busca deve viabilizar análises mais aprofundadas das políticas públicas, possibilitando a identificar seus 


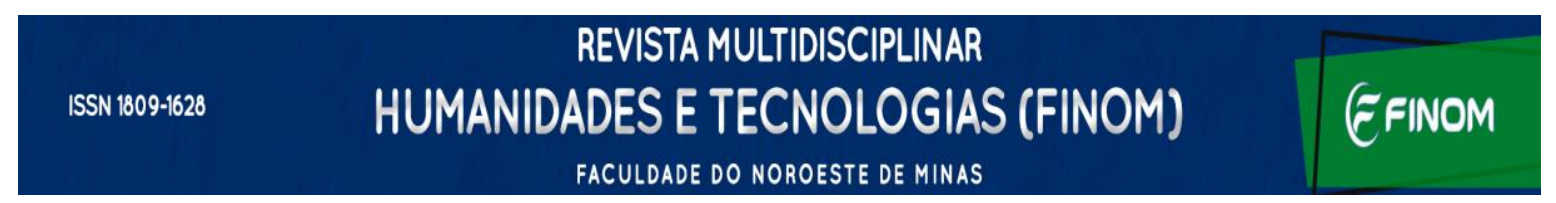

avanços, limitações e desafios na efetivação de direitos sociais.

Diante do exposto, nos propomos a discutir o descritor da desigualdade socioeconômica visto que aglutinam e revelam características da vulnerabilidade social manifestas na escola.

\section{Resultados e discussão}

O descritor desigualdade socioeconômica abrange temáticas relacionadas à garantia do direito à vida, à diversidade étnico-racial, cultural, de gênero; à inclusão/exclusão social e educacional, bem como, à condição de acesso a bens e serviços públicos (saúde, educação, saneamento, esporte, lazer, cultura, transporte, segurança) e à serviços da relação de consumo (redes bancárias, supermercados, farmácias, telefonia e acessibilidade informacional-internet etc.) e seus reflexos e relações no processo de ensino-aprendizagem.

No âmbito da escola, as desigualdades se revelam sob diferentes formas, evidenciando relações sociais marcadas por contradições e antagonismos históricos. Exemplo disso, podemos citar, as disparidades nas condições de acesso e de permanência dos estudantes; as vulnerabilidades de várias ordens; questões infraestruturais (condições objetivas da realidade das escolas, como: a qualidade e a quantidade de materiais, objetos e mobílias, recursos tecnológicos, acessibilidade etc.) e relacionadas a qualificação e valorização dos profissionais da educação, entre outros, que revelam insuficiências, fragilidades e/ou ineficiências das políticas atuais quanto à provisão de condicionantes necessários à fruição de direitos fundamentais por aqueles que frequentam/atuam na escola.

A análise do descritor desigualdade socioeconômica leva em consideração fatores relacionados com o modo de vida dos sujeitos deste estudo, perpassando as condições em que sua cidadania é exercida, e remete-se aos processos existentes dentro das relações sociais, profissionais, políticas e econômicas manifestas no ambiente escolar.

Os dados mostram que, para 41,5\% dos respondentes, a desigualdade socioeconômica é um tema que deve ser discutido nas escolas estaduais paulistas. Por outro lado, $51,4 \%$ dos respondentes indicaram este descritor dentre aqueles que já vêm sendo discutidos em suas unidades escolares, situando-o entre os dez mais votados.

O Plano Estadual de Educação (PEE- 2016-2026) traz como uma de suas diretrizes, a superação das desigualdades educacionais, com ênfase na promoção da cidadania e na 


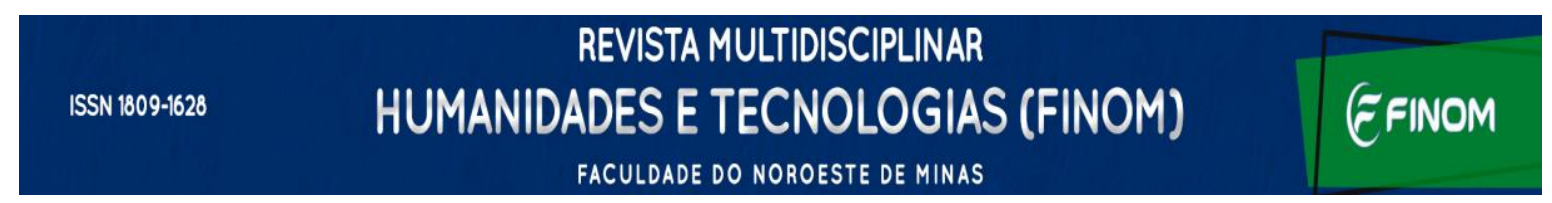

erradicação de todas as formas de discriminação. Considerando-a, ressaltamos a necessidade de cada unidade escolar, em interlocução com agentes do território onde está inserida e pautando-se numa perspectiva de educação emancipatória, refletir criticamente sobre sua realidade e propor mudanças que melhorem as condições de vida e educação.

Nesse sentido, a Meta 20, do PEE apresenta-se como importante instrumento de equalização na garantia do direito à educação pública de qualidade, no combate da vulnerabilidade socioeconômica e no compromisso técnico e de gestão do sistema de ensino (SÃO PAULO, 2016).

Na continuidade, a pesquisa mostrou que, para 29,9\% dos respondentes, as desigualdades socioeconômicas ainda são um fator desafiante e requer maior atenção do Estado, via políticas públicas que resultem efetivamente na qualidade de vida da população e, igualmente, na qualidade da educação pública ofertada. Isto exige, entre outros aspectos, a formação contínua e a valorização dos profissionais do magistério, conforme estabelecem as Metas 17,18 e 21 do PEE-SP.

\section{A função da escola no combate às desigualdades}

Sabemos que o currículo e as políticas de avaliação têm um papel decisivo no combate das desigualdades que se manifestam na escola. Assim, quando questionados sobre qual deveria ser a principal função da escola, os respondentes consideraram: formar para a vida $(33,2 \%)$; formação integral da pessoa $(30,6 \%)$, formar o cidadão $(19,2 \%)$ e transformação social (11\%). Apenas 3,5\% dos respondentes consideraram que a função da escola é a transmissão de conteúdos.

Em seguida, os respondentes avaliaram se a escola pública da atualidade cumpre sua função principal: 63,6\% disseram que não, e apontaram que, hoje, a escola tem centrado-se em acolher o estudante e transmitir conteúdo.

Refletir sobre qual é e/ou qual deve ser a função da escola é fundamental, especialmente neste período de forte turbulência social (SANTOS, 2020) causada pela pandemia do coronavírus. $\mathrm{O}$ acolhimento dos jovens estudantes e a promoção de um conjunto de saberes novos, especializados e significativos, os quais muitas vezes não estão acessíveis nos seus contextos familiares e comunitários etc. (YOUNG, 2007), constituem a função da escola de formar integralmente os indivíduos, para que sejam capazes de enfrentar os desafios 


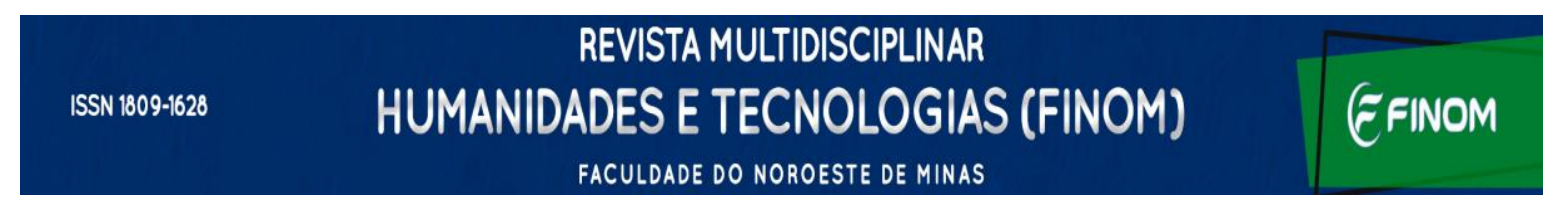

advindos dos diferentes âmbitos da vida em sociedade. Formar para a vida, formar integralmente a pessoa e formar cidadãos, são ideais de escola que se conectam semântica e utopicamente. Não são, portanto, divergentes da finalidade desta instituição que é a de transmitir saberes e promover espaços de diálogo, de interações e trocas entre pessoas de gerações distintas, de maneira intencional, pedagógica e acolhedora. Quando se fala em “transmissão de conteúdos”, precisamos indagar quais os sentidos e significações presentes nessa fala, quais relações e experiências denota, quem são os interlocutores e qual seu lugar fala. Ademais, a relevância da escola está promover o conhecimento (YOUNG, MULLER, 2016) com base em metodologias que reconheçam o valor das experiências dos estudantes, que dialoguem com e respondam às suas diferentes expectativas, interesses e necessidades formativas.

Os dados, a nosso ver, acenam com a necessidade de melhor compreensão das possibilidades e limitações do trabalho educativo, bem como das contradições inerentes à escola. Com base em Zabala (2011), para a escola cumprir com a função de formar para a vida, isto é: preparar meninos(as), jovens e adultos(as) para o exercício pleno e crítico de sua cidadania, contribuindo com soluções favoráveis a manutenção do estado democrático de direito, ela deverá "estabelecer o tipo de cidadão e cidadania que a sociedade necessita para ser cada vez melhor" . E na continuidade este autor explica: "A educação só tem sentido quando está a serviço de ideais. Quanto mais distantes estejam esses ideais da realidade, maiores devem ser os meios de que tem de lançar mão a escola” (ZABALA, 2011, s/p.).

O entendimento expresso pela proposta curricular da Rede Estadual de Ensino de São Paulo compreende a inclusão de conteúdos socioculturais nos planos de aula e diálogos que estabelecidos no cotidiano das escolas, os quais devem levar os sujeitos a uma reflexão sobre os efeitos produzidos por relações assimétricas marcadas pela desigualdade, observadas no seu contexto histórico e no mundo atual (SÃO PAULO, 2010, p.159). Para que a escola cumpra com as finalidades apontadas pelos sujeitos, será necessário, valendo-nos das palavras de Zabala e Arnau (2014, p.94), “desenvolver a sensibilidade diante do sofrimento humano, estimulando o compromisso vital com a justiça e com a igualdade, sobretudo em uma sociedade cada vez mais insensível devido à rápida e abundante informação de conflitos e misérias".

Young (2007, p. 1301) alerta que resolver "os problemas dessa tensão entre demandas políticas e realidades educativas [...] é uma das maiores questões educativas dos nossos 


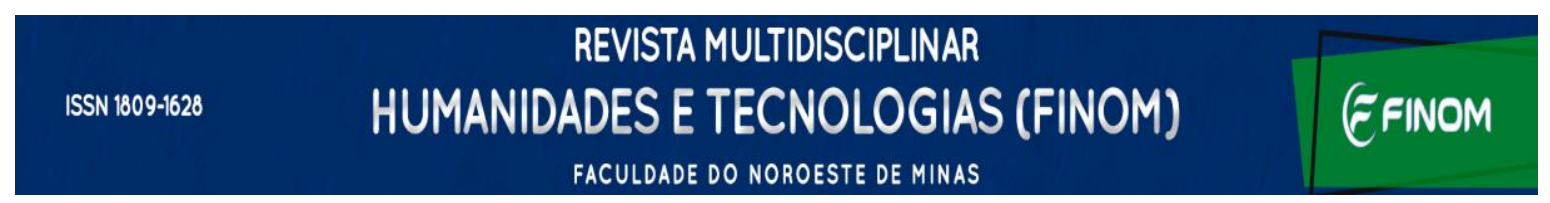

tempos" (1301). E completa, afirmando que a finalidade essencial das escolas é a de promover a aquisição de um conjunto de saberes novos, especializados, - os quais ele denomina conhecimento poderoso. Garantir a aquisição do conhecimento poderoso é uma via possível para a problematização e busca de alternativas, no tempo presente, para romper com "mecanismos que produzem injustiça, [...] divisão social, desigualdade, infelicidade e conflito" (YOUNG, MULLER, 2016, p.535-536).

A educação como instrumento de transformação social é amplamente divulgada nos meios acadêmico, científico, político e midiático, embora estes últimos nem sempre apresentem interesses discursivos alinhados aos demais. Depreendemos dos dados, produzidos a partir das experiências dos sujeitos participantes do estudo, que essa visão compreende o esforço e o anseio coletivo de uma escola democrática, justa e equitativa, que tem como princípio norteador de suas ações, a busca pela garantia dos direitos humanos, conforme estabelecem as Diretrizes Curriculares Nacionais da Educação Básica (DCNEB) (BRASIL, 2013).

De acordo com Zabala e Arnau (2013, p.13) , a educação como prática social deve buscar "responder a situações, conflitos e problemas relacionados à vida real, [...] respeitando as características de cada aluno", acrescentamos, e cada docente e demais atores envolvidos direta ou indiretamente com os processos educativos numa perspectiva emancipadora. Assim, outro ponto salutar, será a compreensão e a necessária intervenção, via políticas públicas, para a valorização dos profissionais da educação, a fim de superação dos desafios relacionados às condições de trabalho (formação, jornada, adequação e suficiência de recursos, salário digno, segurança) nas escolas. Deve-se ressaltar que, para 53,8\% dos respondentes da pesquisa, as condições de trabalho apresentam muitos desafios à realização da atividade profissional, em seguida tem-se a falta de reconhecimento social da profissão docente $(14,2 \%)$ e a necessidade de formação continuada (10,4\%). Esses desafios, em nosso entendimento, refletem as tensões e conflitos de interesses presentes na sociedade em geral, e exigem melhor atenção aos propósitos e fins específicos da educação pública.

Desse modo, consideramos de fundamental importância um outro olhar para a questão das desigualdades presentes na escola pública da atualidade, as quais revelam questões de urgente solução nas esferas mais amplas da sociedade, que, conforme Ronca (2015) segue profundamente marcada por inequidades sociais e econômicas que alargam o abismo social entre as populações minorizadas historicamente e aquelas pertencentes a estratos sociais mais 


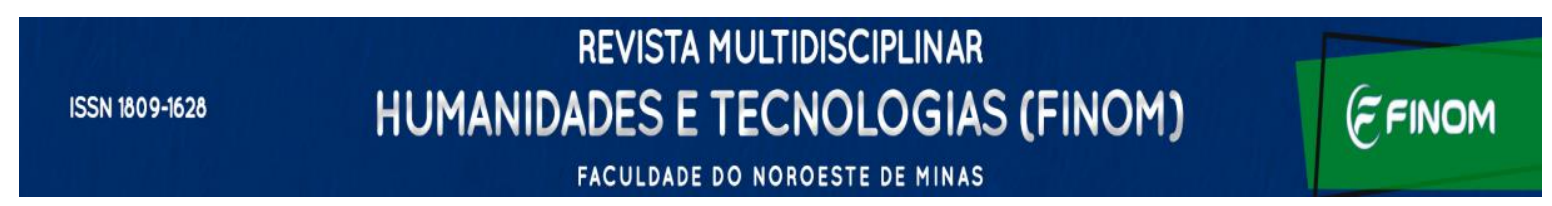

favorecidos.

\section{Considerações finais}

Ao trazermos no título a ideia de utopia, temos em mente que sem ela não há educação (ZABALA, 2011). Para que serve a utopia? Freire (1979, p.27) nos ensina que a utopia não é sinônimo de irrealizável, de idealismo, "é a dialetização dos atos de denunciar e anunciar, denunciar a estrutura desumanizante e de anunciar a estrutura humanizante.

A utopia, neste trabalho, reflete a concepção freireana, ou seja, compreendemos utopia como a possibilidade de concretização de sonhos (im) possíveis nas esferas social e educacional. Assim, ao articular as concepções dos sujeitos aos dados sobre o descritor desigualdades socioeconômicas, nos propomos a denunciar e anunciar tais estruturas, como nos inspira Freire (1979), e chamamos à existência os sonhos e as muitas formas de resistências e (re) existências presentes nas escolas públicas da atualidade.

Com Salgado (2010) e Ronca (2015) entendemos que vidas que habitam a escola paulista, quer sejam estudantes, trabalhadores da educação ou comunidade geral, nenhuma delas pode ser reduzida de sua condição humana. Por isso, é inadiável refletir sobre as desigualdades de oportunidades sociais e educacionais, sobre os processos de exclusão social vividos dentro e fora da escola e sobre o papel e alcance das políticas públicas na realização dos princípios éticos, estéticos e políticos inerentes à educação básica de qualidade, que visam à formação humana integral e à construção de uma sociedade livre, justa e solidária conforme orientam as DCNEB (BRASIL, 2013).

Por fim, consideramos que o desafio colocado à escola, ainda no século XXI, de participar da discussão sobre as enormes desigualdades sociais que se desenham nos diversos cenários educacionais brasileiros, demonstra que os diversos atores da educação possuem papel importante no processo de superação e combate a essas desigualdades. Entretanto, deve existir uma unidade de esforços para que o resultado possa ser ações de combate à essas desigualdades em todas as áreas. Considera-se, portanto, haver necessidade de revisão de políticas educacionais sob um enfoque da intersetorialidade; com atenção para a formação e valorização profissional, melhoria das condições para realização do trabalho do profissional nas instituições escolares do estado de São Paulo, e valorização do estudante como protagonista no processo de ensino-aprendizagem. O combate às desigualdades que se 


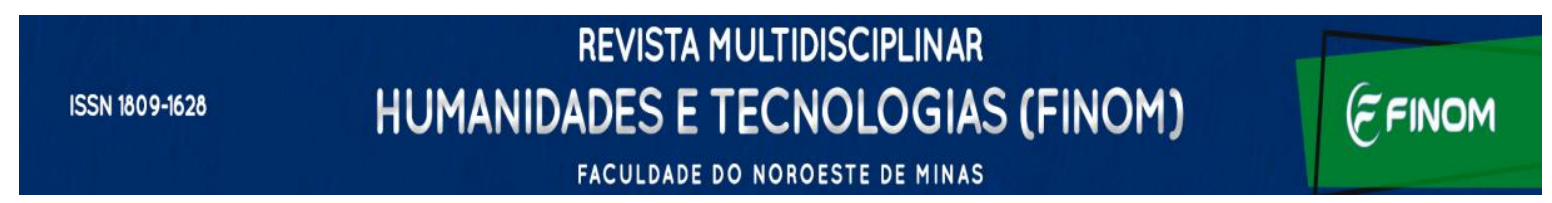

manifestam na escola será possível mediante o fortalecimento de políticas públicas e de políticas e práticas educativas, alinhadas a concepções de aluno/indivíduo, de currículo, de escola e sociedade convergentes com um ideal de sociedade onde se tenha garantido o desenvolvimento nacional e o direito à vida; a erradicação da pobreza e da marginalização; a superação das desigualdades sociais e regionais; e onde o bem de todos seja promovido preconceitos e quaisquer formas de discriminação. Utopias estas que devem nos guiar na direção da humanidade, e sem as quais, a reprodução de estruturas desumanizantes nutre cada vez mais, a desesperança.

\section{Referências}

ADORNO, R. C. F. Um olhar sobre os jovens e sua vulnerabilidade social. São Paulo: AAPCS -Associação de Apoio ao Programa Capacitação Solidária, 2001.

BRASIL. Constituição (1988). Constituição da República Federativa do Brasil de 1988. Brasília, $1988 . \quad$ Disponível em: <http://www.planalto.gov.br/ccivil_03/constituicao/constituicao.htm>. Acesso em: 27 fev. 2017.

BRASIL. Ministério da Educação. Secretaria de Educação Básica; Secretaria de Educação Continuada, Alfabetização, Diversidade e Inclusão. Secretaria de Educação Profissional e Tecnológica. Conselho Nacional de Educação; Câmara de Educação Básica. Diretrizes Curriculares Nacionais da Educação Básica. Brasília: MEC; SEB; DICEI, 2013. Disponível em: $<$ http://portal.mec.gov.br/index.php?option=com_docman\&view=download\&alias=13448diretrizes-curiculares-nacionais-2013-pdf\&category_slug=junho-2013-pdf\&Itemid=30192> Acesso em: 19 dez.2021

CARMO, M. E. do; GUIZARDI, F. L.. O conceito de vulnerabilidade e seus sentidos para as políticas públicas de saúde e assistência social. ( Ensaio) Cad. Saúde Pública, v. 34, n. 3, p. 1-14, 2018. Disponível em: <https://www.scielo.br/j/csp/a/ywYD8gCqRGg6RrNmsYn8WHv/>. Acesso em: $15 \mathrm{dez}$. 2021. https://doi.org/10.1590/0102-311X00101417

FREIRE, P. Conscientização: teoria e prática da libertação. São Paulo: Cortez \& Moraes, 1979.

MANN J.; TARANTOLA, D.J.M.; NETTER, T.W. Aids in the world. Cambridge: Harvard University Press; 1992.

MAY, T. Pesquisa social: questões, métodos e processos. 3 ed. Porto Alegre, RS: Artmed, 2004.

MONTEIRO, S. R. da R. P. O marco conceitual da vulnerabilidade social. Sociedade em Debate, [S.1.], v. 17, n. 2, p. 29-40, 2012. Disponível em: https://revistas.ucpel.edu.br/rsd/article/view/695. Acesso em: 15 dez. 2021. 


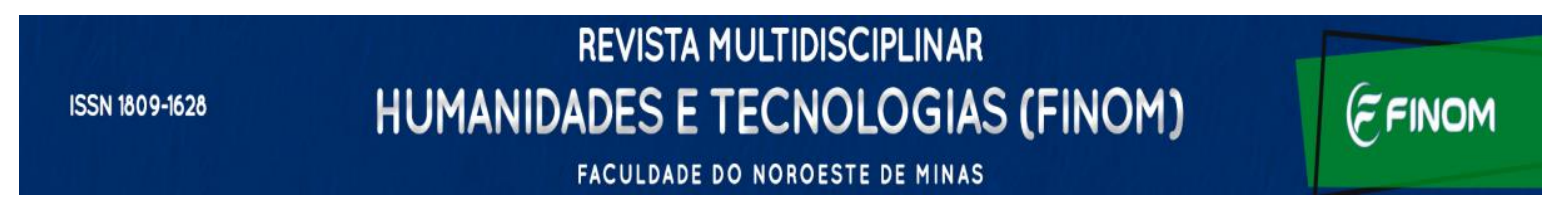

RAOPORT, Andrea; DA SILVA, S. B. Desempenho escolar de crianças em situação de vulnerabilidade social. Revista Educação em Rede: Formação e Prática docente [S.1.], v. 2, n. 2, abr. 2013. 2 Disponível <http://ojs.cesuca.edu.br/index.php/educacaoemrede/article/view/410>. Acesso em: $12 \mathrm{dez}$. 2021.

RONCA, A. C. C. A qualidade da Educação: políticas públicas e equidade. In: RONCA, A. C. C. ALVES, L. R. (Org.). O Plano Nacional de Educação e o Sistema Nacional de Educação: educar para a equidade. São Paulo: Fundação Santillana, 2015, p. 95-109.

SALGADO, J.A. Desigualdade social. In: OLIVEIRA, D.A.; DUARTE, A.M.C.; VIEIRA, L.M.F. DICIONÁRIO: trabalho, profissão e condição docente. Belo Horizonte: UFMG/Faculdade de Educação, 2010. Disponível em: <https://gestrado.net.br/wpcontent/uploads/2020/08/127.pdf>. Acesso em: 16 dez. 2021

SANTOS, Boaventura de Sousa. A cruel pedagogia do vírus. Coimbra: Edições Almedina, 2020.

SÃO PAUlO (Estado). Secretaria da Educação. Currículo do Estado de São Paulo: Linguagens, códigos e suas tecnologias. Secretaria da Educação; coordenação geral, Maria Inês Fini; coordenação de área, Alice Vieira. -2. ed. São Paulo: SE, 2011.

SÃO PAULO (Estado). Lei no 16.279, de 08 de julho de 2016. Aprova o Plano Estadual de Educação de São Paulo e dá outras providências. Disponível em: <https://www.al.sp.gov.br/repositorio/legislacao/lei/2016/lei-16279-08.07.2016.html>.

Acesso em: 16 dez. 2021.

SÃO PAUlO (Estado). Resolução SE, de 16 de dezembro de 2019. Dispõe sobre a carga horária dos docentes da rede estadual de ensino.

SÃO PAUlO (Estado). Secretaria da Educação de São Paulo. Diretrizes do Programa de Ensino Integral. São Paulo: Seduc-SP, s/d. Disponível em: <https://www.educacao.sp.gov.br/a2sitebox/arquivos/documentos/342.pdf >. Acesso em: 16 dez. 2021.

SÃO PAUlO (Estado). Secretaria da Educação de São Paulo. Tutorial de Recursos Humanos Programa Ensino Integral. São Paulo: Seduc-SP, s/d. Disponível em: <https://www.educacao.sp.gov.br/a2sitebox/arquivos/documentos/343.pdf>. Acesso em: 16 dez. 2021.

SCOTT, Juliano Beck et al. O conceito de vulnerabilidade social no âmbito da psicologia no Brasil: uma revisão sistemática da literatura. Psicologia em Revista, Belo Horizonte, v.24, n.2, 2018, p.600-615. Disponível em: http://periodicos.pucminas.br/index.php/psicologiaemrevista/article/view/9195/14050 Acesso em: 13 dez.2021

ZABALA, Antoni. Educar para a Vida. Entrevista concedida à Constança Guimarães, 10 set. 2011, Rev. Educação. Disponível <https://revistaeducacao.com.br/2011/09/10/educar-para-a-vida/> Acesso em: 16 dez. 2021.

ZABALA, Antoni. ARNAU, Laia. Como aprender e ensinar competências [recurso eletrônico]. Tradução: Carlos Henrique Lucas Lima; revisão técnica: Maria da Graça Souza Horn. Porto Alegre: Penso, 2014. 